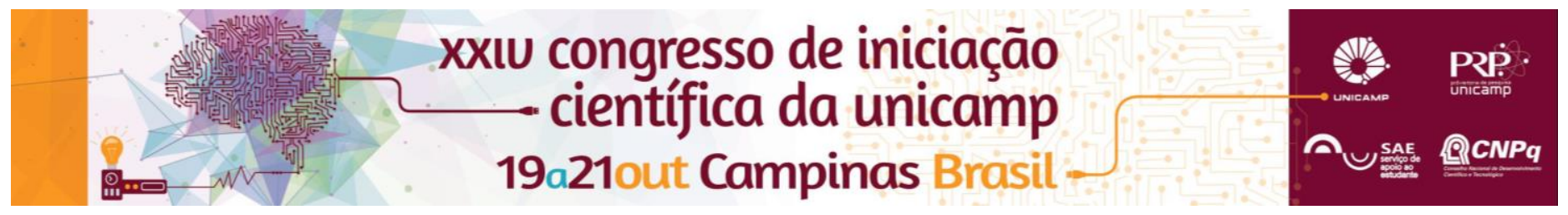

\title{
Articulando diferenças: raça e sexualidades na literatura sobre diversidade sexual no Brasil
}

\author{
Autor: Bruno Ribeiro Ferreira*
}

\begin{abstract}
Resumo
Esta pesquisa tem por objetivo realizar uma revisão crítica acerca da produção antropológica articulando os marcadores de raça e sexualidade no campo de estudos de diversidade sexual no Brasil, a partir do período de institucionalização das Ciências Sociais na década de 1960. Tal objetivo mobiliza um campo de questões centrais à trajetória da produção antropológica no Brasil, mesmo antes de sua consolidação enquanto campo disciplinar, marcado pelo interesse suscitado pela diferença, abordada em distintos momentos e sob variadas perspectivas teóricas.
\end{abstract}

\section{Palavras-chave}

Raça, sexualidades, antropologia.

\section{Introdução}

O presente estudo trata-se de uma revisão crítica sobre a produção antropológica articulando os marcadores de raça e sexualidade no campo de estudos de diversidade sexual a partir de 1960, momento em que foi institucionalizado os programas de pós-graduações no Brasil. Tal estudo dialoga com uma série de questões centrais à trajetória da produção antropológica no Brasil, mesmo antes de sua consolidação enquanto campo disciplinar, marcado pelo interesse suscitado pela diferença, sob variadas perspectivas teóricas, nos debates sobre mestiçagem de fins do século XIX, nas pesquisas sobre as origens da sífilis nas décadas de 1920 e 1930, nas discussões sobre o candomblé e a homossexualidade até os contemporâneos estudos sobre "interseccionalidades" e marcadores sociais da diferença.

\section{Resultados e Discussão}

A metodologia do projeto se apoiou em estratégias já bastante consolidadas no que concerne a levantamentos bibliográficos e sua qualificação a partir de um problema de pesquisa específico - no caso, aqui, a articulação entre raça e sexualidade nos trabalhos do campo de estudos sobre diversidade sexual. Vale notar que, tal como destaca Mariza Corrêa (2000) ${ }^{1}$, este entrecruzamento é pertinente para a compreensão da formação do território da antropologia, como um campo disciplinar no Brasil.

Neste sentido, partiu-se da leitura e fichamento de 6 "trabalhos de referência" que continham uma revisão que incorporasse a articulação de diferenças dentro dos estudos sobre diversidade sexual e reflexões acerca das diferentes abordagens teóricas para diferenças. Junto aos fichamentos foi iniciada a construção de um banco de dados e a inserção de informações (nome, ano, programa de pós-graduação, marco teórico, observações, autor, universidade, entre outras), por meio de análise nas bibliografias dos artigos fichados. Para isso, foram verificados, bibliografias de trabalhos e currículos Lattes de pesquisadores da área de diversidade sexual, o Banco de Teses da CAPES (http://bancodeteses.capes.gov.br/) a Biblioteca Digital Brasileira de Teses e Dissertações (http://bdtd.ibict.br/), a base Scielo (www.scielo.org/) e repositórios online de 26 instituições com programa de pós-graduação em antropologia, nas 5 regiões do país.

Para análise, foram selecionadas cerca de 60 teses e dissertações produzidas, em sua maioria, a partir dos anos 2000. Uma inflexão importante: se o aumento do número de pesquisas pode ser explicado como um reflexo de políticas de expansão do ensino superior, o aumento de linhas de pesquisa sobre diversidade sexual e de gênero e o crescente esforço de se pensar marcadores sociais da diferença na última década (SIMÕES e CARRARA, 2014) contribuíram para que os entrecruzamentos de raça e sexualidade ganhassem centralidade em diversas pesquisas recentes.

Assim, se há poucos trabalhos tomando sexualidade como central no campo dos estudos sobre relações raciais, conforme afirma Moutinho (2014) ${ }^{3}$, no campo dos estudos de diversidade sexual e de gênero há uma produção que tem se empenhado no sentido de articular categorias e fazer dialogar diferentes tradições teóricas, nacionais e internacionais ampliando o olhar para as diferenças e seus pontos de articulação.

\section{Conclusões}

Foi possível demonstrar que a trajetória da produção antropológica brasileira é marcada por fios condutores que revelam um olhar para a produção da diferença, cujos os entrecruzamentos entre raça e sexualidade ocupam um papel central. Delineou-se também eixos centrais dos debates por meio de um banco de dados que se tornou uma possibilidade, um olhar para a importante contribuição dos estudos sobre diversidade sexual que remonta uma parte da história de formação e consolidação da antropologia enquanto disciplina no Brasil.

Desta forma, esta revisão denota a importância de se olhar de modo panorâmico para a produção antropológica e compreendê-la em articulação com suas perspectivas teóricas.

\section{Agradecimentos}

Agradeço ao $\mathrm{PIBIC} / \mathrm{CNPq}$ pelo financiamento deste estudo. À Isadora Lins França que me orientou de modo primoroso e me estimulou a realizar esta pesquisa. À Regina Facchini, à todas e a todos do grupo de pesquisa que contribuíram grandemente à minha pesquisa com comentários muito ricos.

CORRÊA, Mariza. O mistério dos orixás e das bonecas: raça e gênero na antropologia brasileira. Etnográfica, vol. IV, nํ2, Lisboa-Portugal, 2000, pp.233-266.

MOUTINHO, Laura. Diferenças e desigualdades negociadas: raça, sexualidade e gênero em produções acadêmicas recentes. Cadernos Pagu, Campinas, v. 1, p. 201-248, 2014

SIMÕES, Júlio A.; CARRARA, Sérgio. O campo de estudos socioantropológicos sobre diversidade sexual e de gênero no Brasil: ensaio sobre sujeitos, temas e abordagens. Cadernos Pagu, Campinas, v. 42, p. 75-98, 2014. 